Journal of Advanced Research in Fluid Mechanics and Thermal Sciences

\title{
Performance Analysis of Z-Blade Reaction Type Turbine for Low-Head Low Flowrate Pico Hydro
}

\author{
Mohd Farriz Basar ${ }^{1,}{ }^{*}$, Fatin Syakira Mohd Hassan ${ }^{1}$, Nurul Ashikin Rais ${ }^{1}$, Izzatie Akmal Zulkarnain ${ }^{1}$, \\ Wan Azani Wan Mustafa²
1 Faculty of Electrical and Electronic Engineering Technology, Universiti Teknikal Malaysia Melaka, Hang Tuah Jaya, 76100 Durian Tunggal, Melaka, Malaysia \\ 2 Center of Excellence Geopolymer and Green Technology, Universiti Malaysia Perlis, 01000 Kangar, Perlis, Malaysia
}

\begin{tabular}{l} 
ARTICLE INFO $\quad$ ABSTRACT \\
\hline
\end{tabular}

\section{Article history:}

Received 11 April 2021

Received in revised form 19 June 2021

Accepted 25 June 2021

Available online 5 August 2021

\section{Keywords:}

Low flow; low head; pico-hydro; reaction turbine; Z-Blade

\begin{abstract}
The study explores the performance characteristics of a Z-Blade reaction type water turbine and investigates a test unit for an ideal and practical case using the governing equations derived from the principles of conservation of mass, momentum, and energy. Various analyses are conducted with consideration of the ideal and possible operating condition for low-head ( $3 \mathrm{~m}$ to $5 \mathrm{~m}$ ) and low flowrate ( $2.5 \mathrm{~L} / \mathrm{sec}$ and below) water resources. The relationship of the fluid flow friction known as $\mathrm{k}$-factor with mass flow rate and angular velocity for a Z-Blade turbine model is discussed. The measured performance of two PVC pipe sizes ( 0.5 inch and 1 inch) of a Z-Blade turbine is presented and evaluated against theoretical results. This work also describes the simple concept of a Z-Blade turbine for a pico-hydro application. A large variation in k-factor with a $1 \%$ difference in rotational speed and mass flow rate is presented. The coefficient $\mathrm{k}$-factor is also demonstrated as a strong parameter influencing the mass flow rate and rotational speed performance. This coefficient also has a significant impact on the conversion of potential energy into power output.
\end{abstract}

\section{Introduction}

Among the turbine technologies used for hydropower generation worldwide is the reaction-type water turbine [1-3]. The gardening water sprinkler is one of the simplest examples of a reaction water turbine that illustrates its working principle [4,5]. In reaction turbine, liquid is pressurised, and it flows through the guiding mechanism to rotate the moving blades or moving nozzle [6-8]. As the water glides through the moving blades, pressure is reduced, and the velocity of the water stream relative to the moving parts is increased [9-11]. The pressure not only comes from the potential energy but also from the centrifugal head attributed to the self-pumping effect during turbine rotation [12-14].

This research has been inspired by the cross pipe turbine (CPT) and split reaction turbine (SRT) proposed by Date [15-17]. The CPT and SRT are both categorised as simple reaction pico-hydro

\footnotetext{
* Corresponding author.

E-mail address: mfarriz@utem.edu.my
}

https://doi.org/10.37934/arfmts.85.2.5165 
turbines, but only the latter is capable of operating under low-head conditions. Both turbine prototypes exhibit similar characteristics, with the value of the k-factor having a tendency to increase with the increment of mass flow rate [7].

At present, Z-blade reaction turbine is considered suitable for low head and low flow water conditions. Even though the potential energy available at low head and low flow is lower than that of a traditional water dam, the potential extracted energy efficiency of pico-hydro can be significant with proper turbine design. This situation prompted this research to concentrate on the turbine design in order to develop a novel approach to the low head and low flow pico-hydro method.

Under real operating conditions, energy loss is associated with the flow of water through the ZBlade turbine $[1,10,18]$. This paper discusses in detail the factor that would represent the loss of fluid frictional energy associated with the fluid flow through the Z-Blade turbine. This factor, known throughout this paper as the "k-factor", will have a significant impact on the overall performance of the water turbine of the Z-Blade reaction type.

Meanwhile, the performance of the Z-Blade turbine is predicted with a few modifications to the approach used in testing the CPT and SRT. The high-pressure pump is replaced with a water tank, such that a source of water with a natural flow rate attributable to gravitational force can be applied to the turbine. Furthermore, the use of a water pump [11,18] is most likely suitable for high and controllable flow rates. The Z-Blade prototype was tested under low head ( $3 \mathrm{~m}$ to $5 \mathrm{~m}$ ) and extremely low flow $(\leq 2.5 \mathrm{~L} / \mathrm{sec})$ conditions.

In addition, this work explores the performance characteristics of a Z-Blade turbine under ideal and practical conditions for different nominal diameters of PVC pipes used for the turbine. The optimum turbine diameter and the maximum rotational speed at different water head levels with various k-factor values are then predicted and discussed. Furthermore, the relationship of the kfactor, which closely relates to turbine efficiency, with the mass flow rate, turbine diameter, water head, and angular velocity of the rotor were investigated based on the experimental results. This study also discusses the measured performance of a Z-Blade turbine based on the power and efficiency curves drawn from experimental data. Furthermore, the k-factor, as a strong function of the performance of the Z-Blade turbine, is confirmed and presented.

\section{Z-Blade Concept Design}

The development of the Z-Blade turbine is based on the design, experimental investigations, and parametric analysis of the CPT, which has been developed and discussed by Date et al., $[7,16]$. The CPT using 3" standard galvanized iron pipe (GI) fittings such as one unit of a 3 " cross at the center, two units of arms made of 3 " male adapter fittings, two units of 3 " to 2 " reduction elbows, and 5/8" solid stream jet nozzles. At both ends of the pipes, the nozzle is mounted to cause the water to flow out tangentially towards the rotor diameter, thus maximizing the thrust of the water flowing out of the nozzle [17].

Date et al., [16] stated that the turbine diameter must be significantly small (approximately $0.4 \mathrm{~m}$ ) to enable the CPT to spin at faster speeds. However, building the CPT to have the desired small diameter is very difficult when using standard galvanized iron (GI) pipe fittings. The smallest diameter can be made is using the standard 3' pipe cross is $0.4 \mathrm{~m}$. Moreover, by using $80 \mathrm{kPa}$ water pressure and the shortest diameter, the maximum speed of a CPT under no-load conditions is only $530 \mathrm{rpm}$ with turbine efficiency of approximately 55\% [15]. After the exploratory works on CPT, this type of turbine was found to be incapable of producing power output efficiently for low-head hydro, and further works on CPT were no longer pursued [7]. 
In order to design the Z-blade to perform effectively under low-head and low flowrate water conditions, some major modifications have been made to the CPT design. Instead of galvanized iron (GI) pipe, this innovative Z-blade turbine uses standard grey Class D PVC pipe fittings. Compared to GI pipes, the PVC pipe is inexpensive, readily available in local hardware stores, and can be easily modified or adjusted to suit a significantly small-sized turbine diameter. The assembly process is also easy to perform, requiring no advanced technical expertise, skilled workers, or high-tech manufacturing machinery. Figure 1 shows the Z-blade turbine used in the experiments with a nominal diameter of PVC pipe, S, varying at $\varnothing 25 \mathrm{~mm}\left(1^{\prime \prime}\right)$ and $\varnothing 15 \mathrm{~mm}\left(1 / 2^{\prime \prime}\right)$.
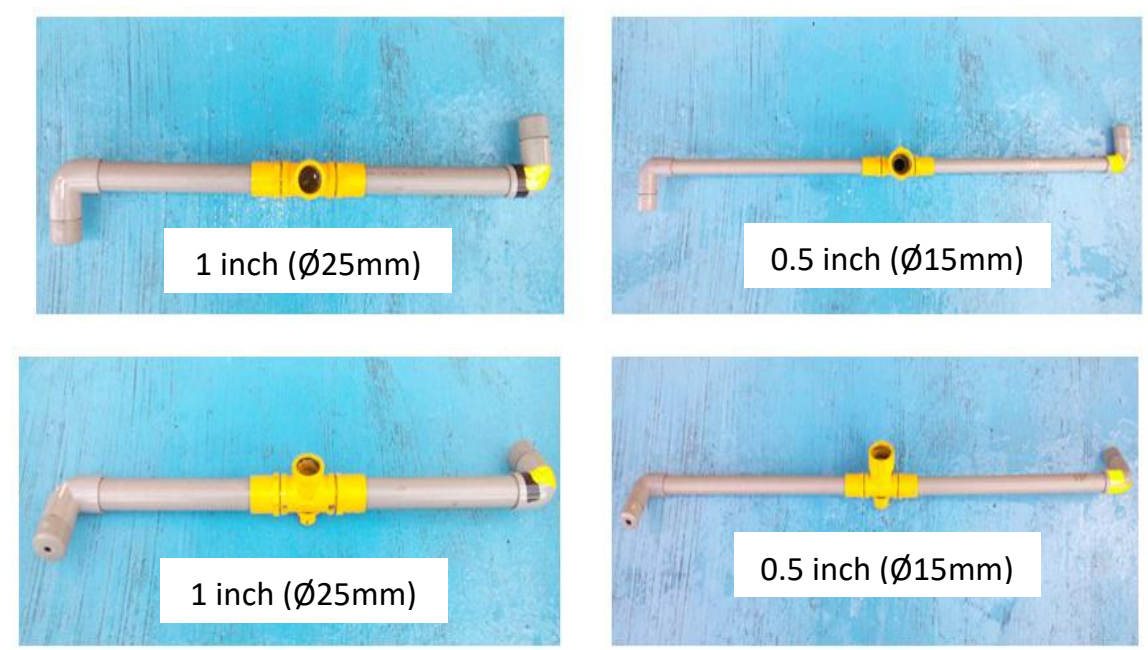

Fig. 1. Size of PVC pipe $\left(\varnothing 25 \mathrm{~mm}\left(1^{\prime \prime}\right)\right.$ and $\left.\varnothing 15 \mathrm{~mm}\left(0.5^{\prime \prime}\right)\right)$

This simple reaction turbine is named Z-blade after its rotor blades, which resemble the letter Z of the alphabet. The Z-blade turbine, as shown in Figure 2, is more economical, with the total cost at USD76, which is almost half of the cost for CPT, which is USD 151 [4]. Due to the simplicity of the fabricating process, the duration of turbine manufacturing is shorter and thus accounts for a cheaper cost of production. The most expensive part is the water coupling, and this is the only part that needs to be customized well. The turbine coupling is not complex and is easy to fabricate compared to the rotary lip seal arrangement used for CPT [18].

A critical part of the Z-blade turbine is the water coupling. It is the meeting point of the stationary pipe and rotating pipe sections. As experienced in the CPT turbine, a significant amount of energy loss occurs in this section and it is mainly related with the V-ring lip seal of the water coupling as the turbine rotates $[15,16]$. Hence, the water coupling for the Z-blade turbine has been carefully designed with minimum coupling friction losses. At the same time, it is also important that the rotary seal arrangement must be able to prevent supplied water to trickle out so that the supplied potential energy is maintained and no water flow or energy is wasted.

In the experimental works, the inlet pipe and coupling housing remains unchanged, even though the nominal diameter of the PVC pipe $S$ is varied from $\varnothing 25 \mathrm{~mm}(1 ")$ to $\varnothing 15 \mathrm{~mm}\left(1 / 2^{\prime \prime}\right)$. However, the other parts such as the T-joint pipe, PVC male threaded adapter, blade's arm, $90^{\circ}$ elbow, and end cap must be changed. 


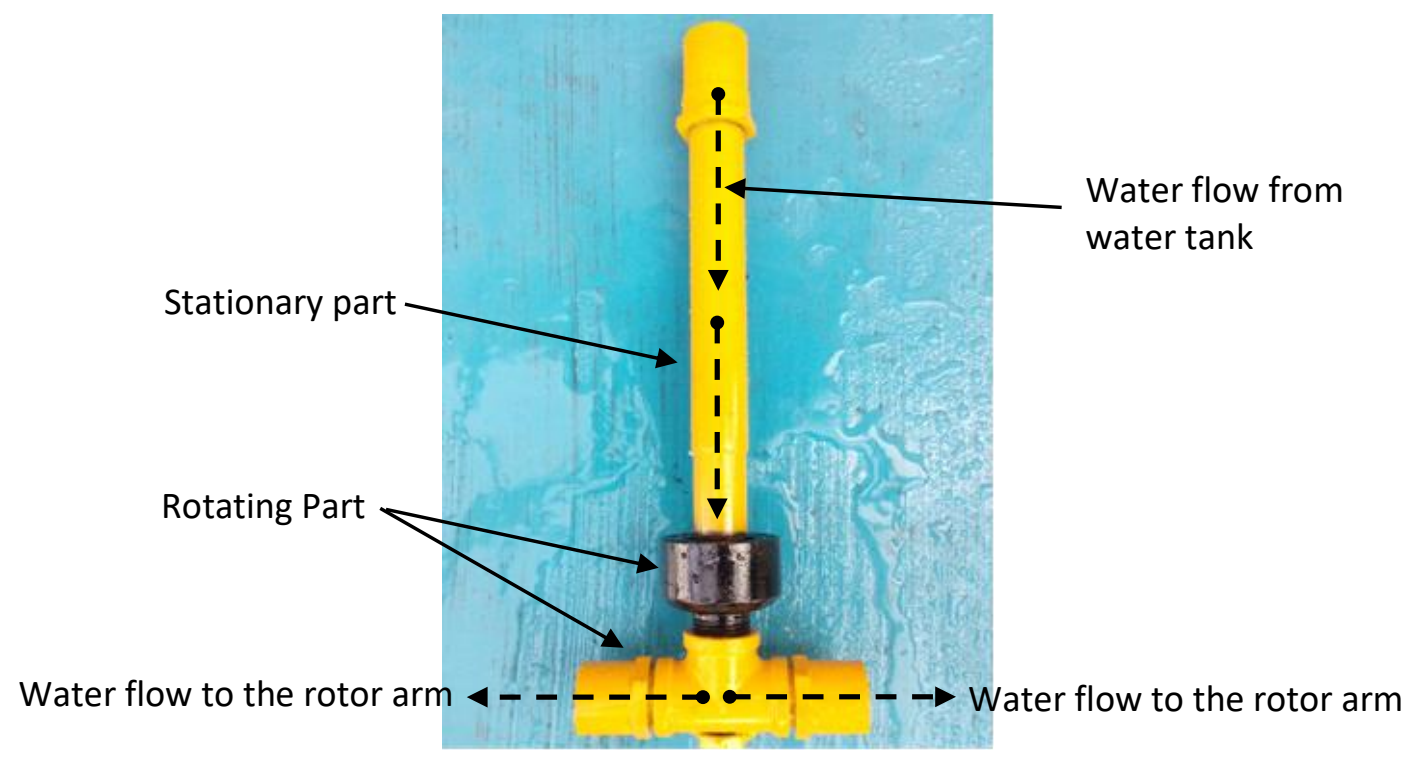

Fig. 2. Z-blade turbine coupling

\section{Experimental Test Rig}

The water head, $\mathrm{H}$, is the most important parameter in hydroelectric, where it is obtained by physical difference between the water level in the reservoir and the position of the turbine $[19,20,22]$. The experimental approach for CPT test rig uses an upward approach to feed the water supply to the turbine. Therefore, the potential energy supplied to Z-blade turbine is greater than CPT $\left(\mathrm{H}_{2}>\mathrm{H}_{1}\right)$. Figure 3 shows that the experimental setup for CPT does not fully utilize the potential energy available at a low-head water supply.

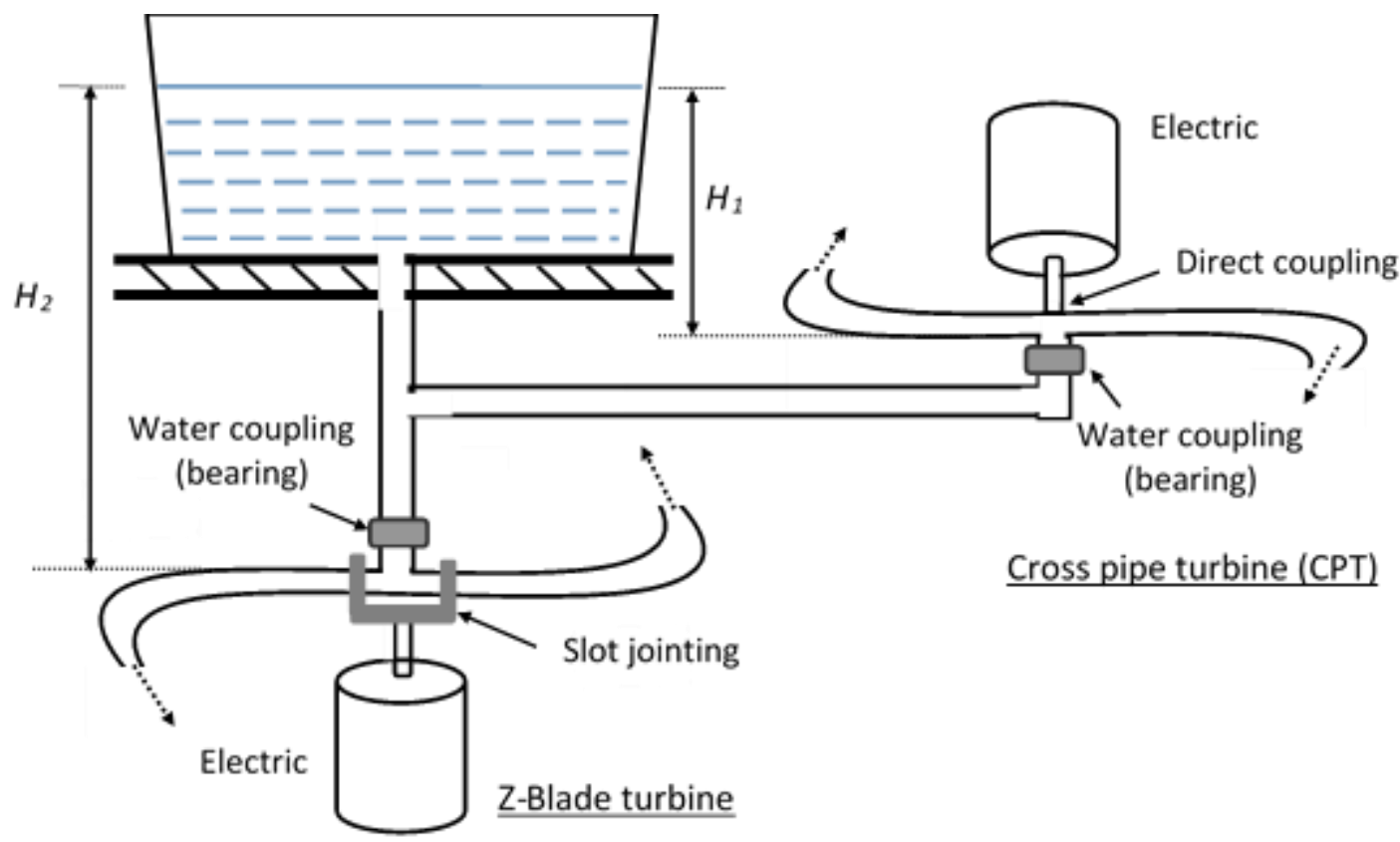

Fig. 3. Schematic of feeding water into the CPT and Z-Blade

This research has, to a certain extent, developed an improved and more effective experimental setup which is easy to assemble and, in addition to that, resembles the near-real condition of the hydro sites. The Z-Blade turbine is tested by feeding the water from the top of the blade, and the 
generator is installed at the bottom of the Z-Blade turbine. With this arrangement, the gravitational potential energy from the water tank is fully utilized. The test rig as shown in Figure 4 can provide up to $5 \mathrm{~m}$ water head and up to 3 liters mass water flow rate. During such an operation, the Z-Blade turbine rotates clockwise when the fluid exits the nozzle tangentially, inducing a reaction force and causing movement of the rotor in the reverse direction of the water jet, simultaneously producing mechanical and electrical power.

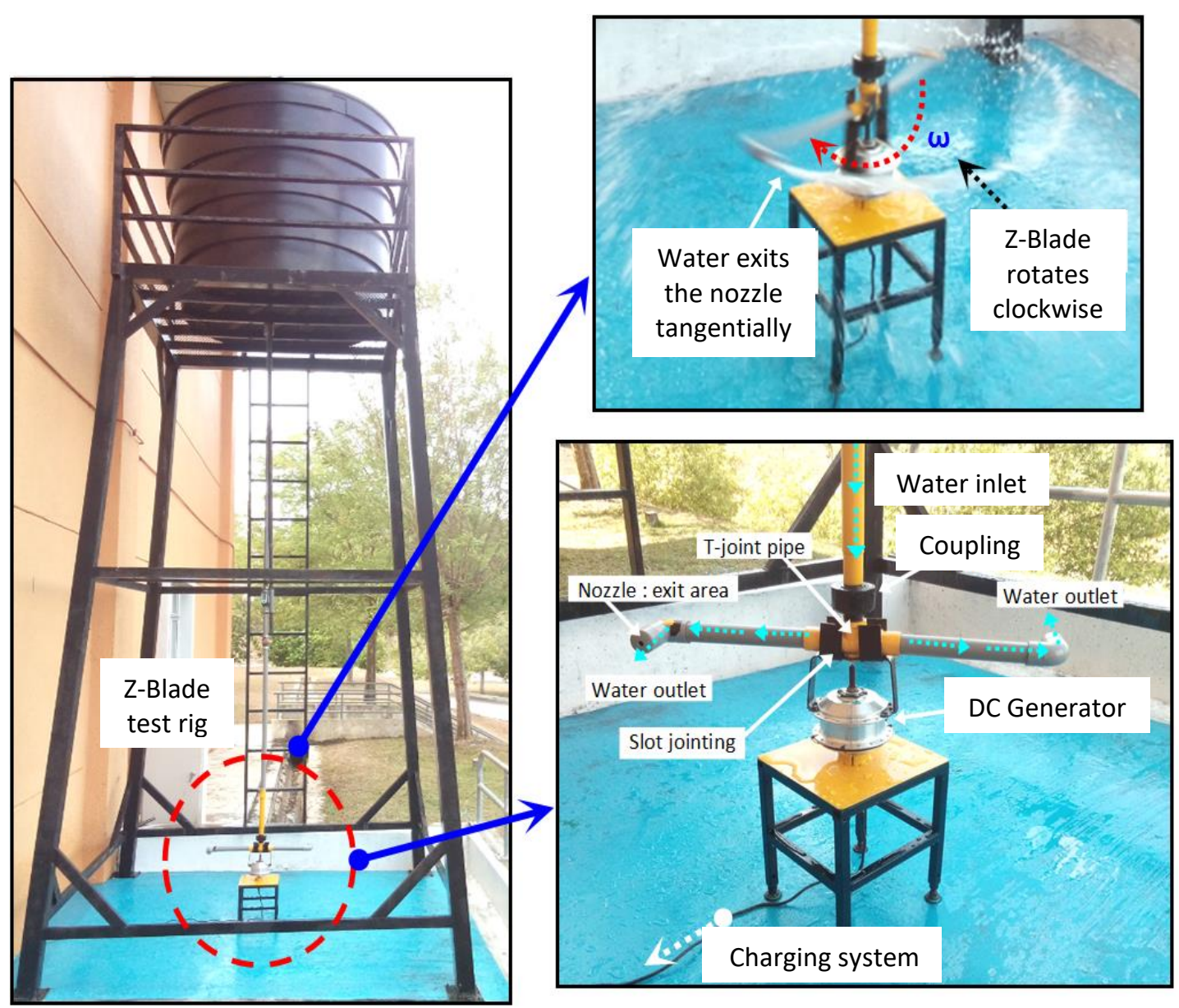

Fig. 4. Z-Blade turbine experimental test rig

\section{Governing Mathematical Model}

The performance of the Z-Blade turbine is predicted by using the governing equations which were developed from the principle of conservation of mass, momentum, and energy [7]. Guided by the theoretical analysis that has been made by $[16,17]$, a few assumptions have been drawn

i. Inability of energy to be dissipated through viscosity.

ii. No turbulence due to its laminar flow characteristic.

iii. Constant water density.

iv. Inconsideration for any losses related to water flow from the reservoir through the piping system.

v. Inconsideration for any mechanical losses such as windage losses caused by the rotation of the turbine.

vi. Inconsideration for any frictional losses of the pipe coupling. 
Following the principle of energy conservation, the gravitational potential energy supplied must be equal to the mechanical work produced and the kinetic energy loss due to the water flowing out at the exiting water jet [15].

$$
\dot{m} g H=\dot{W}+\frac{1}{2} \dot{m} V_{a}^{2}
$$

As shown in Figure 5, the scheme displays the radius of the rotor, the nozzle, and the corresponding velocities.

$$
\begin{aligned}
& U=R \omega \\
& V_{a}=V_{r}-U \\
& V_{a}=V_{r}-R \omega
\end{aligned}
$$

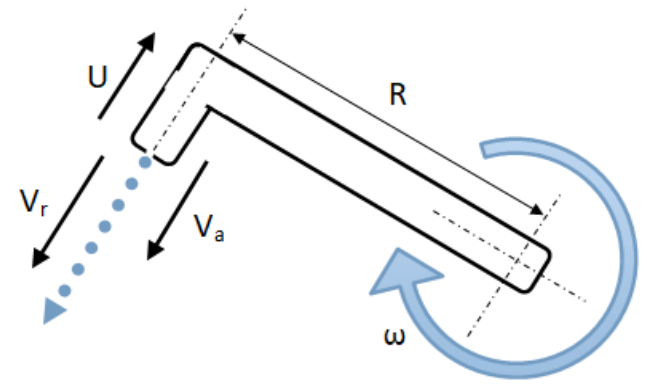

Fig. 5. Scheme of the parameter of the Z-Blade turbine

Ideally, the kinetic energy is equivalent to the sum of the potential energy and the energy generated by the centrifugal head (assuming negligible fluid friction) [7].

$\frac{1}{2} \rho V_{r}^{2}=\rho g\left(H+H_{c}\right)$

The centrifugal head $\mathrm{H}_{c}$ when the turbine is not stationary, $\omega \neq 0$, is calculated as follows

$$
H_{c}=\frac{U^{2}}{2 g}=\frac{R^{2} \omega^{2}}{2 g}
$$

The combination of Eq. (5) and (6) leads to

$$
V_{r}=\sqrt{2 g H+R^{2} \omega^{2}}
$$

Mass flow rate, can be expressed as 
$\dot{m}=\rho A V_{r}$

Hence,

$$
\dot{m}=\rho A \sqrt{2 g H+R^{2} \omega^{2}}
$$

The value of the mass flow rate when the turbine is stationary, $\omega=0$, is calculated as follows

$$
\dot{m}_{S}=\rho A \sqrt{2 g H}
$$

The angular speed of the rotor can be calculated by rewriting Eq. (9)

$$
\omega=\frac{\sqrt{\left(\frac{\dot{m}}{\rho A}\right)^{2}-2 g H}}{R}
$$

Torque is the product of the mass flow rate, the absolute water velocity, and the radius of the turbine

$$
T=\dot{m} V_{a} R
$$

The mechanical output power

$$
\dot{W}=T \omega
$$

The efficiency of the system

$$
\eta=\frac{\dot{W}}{\dot{m} g H}
$$

Adaptation to a real operating situation, the fluid frictional power loss ( $k$-factor) related with the fluid flow through the turbine need to be considered $[7,17]$.

$$
\dot{W}=\dot{m}_{k} g H-\frac{1}{2} \dot{m}_{k} V_{a}^{2}-\frac{1}{2} \dot{m}_{k} k V_{r k}^{2}
$$

By rewriting and combining Eq. (2), (3), (7), (8), (12), (13), and (15) with the k-factor considered, we arrive at

$$
V_{r_{k}}=\sqrt{\frac{1}{1+k}} \times \sqrt{2 g H+R^{2} \omega^{2}}
$$




$$
\begin{aligned}
& V_{r_{k}}=\sqrt{\frac{1}{(1+k)}} V_{r} \\
& V_{r}=(\sqrt{1+k}) V_{r_{k}} \\
& \dot{m}_{k}=\frac{\rho A V_{r_{k}}}{\sqrt{1+k}} \\
& \omega_{k}=\frac{\sqrt{(1+k)\left(\frac{\dot{m}_{k}}{\rho A}\right)^{2}-2 g H}}{R} \\
& k=\frac{2 g H+R^{2} \omega_{k}^{2}}{\left(\frac{\dot{m}_{k}}{\rho A}\right)^{2}-1}
\end{aligned}
$$

$V_{r k}$ is the relative velocity, $\omega_{k}$ is the angular velocity of the rotor, and $m_{k}$ is the mass flow rate of water through a turbine which has been influenced by the k-factor. As described by [7,18], the parameters in Eq. (21) can be obtained from the experimental work.

By knowing the value of $\omega_{k}, m_{k}, V_{r k}$, and the k-factor obtained from the experimental works, the other parameters ( $\mathrm{V}_{\mathrm{ak}}, \mathrm{U}_{\mathrm{k}}$ and etc.) and the overall performance of the Z-Blade turbine at that actual operating condition can be determined. At the same time, by using the value of the $k$-factor and the $V_{r k}$ obtained from the experimental work, the ideal parameters $\left(V_{r}, m\right.$ and $\left.\omega\right)$ can be determined by using Eq. (18), (8), and (11). The symbols $\omega, m$ and $V_{r}$ are presented as ideal values used in the theoretical analysis where no frictional losses have occurred or, in other words, $k$-factor $=0[7,18]$.

\section{Performance of Z-Blade Turbine}

This section explains the assessment and analysis of the Z-blade's performance. Figure 6 and 7 show the theoretical and measured performance curves for the Z-Blade turbine, with the nominal diameter of the PVC pipe being used $\varnothing 25 \mathrm{~mm}\left(1^{\prime \prime}\right)$ and $\varnothing 15 \mathrm{~mm}\left(1 / 2^{\prime \prime}\right)$. Results are presented for various water heads focusing on the $3 \mathrm{~m}, 4 \mathrm{~m}$, and $5 \mathrm{~m}$ water head pressure. Furthermore, the diameter of the turbine is set from $0.3 \mathrm{~m}$ to $2.0 \mathrm{~m}$ and the size of total nozzle exit area, $\mathrm{A}$, is fixed at $1.0 \times 10^{-4} \mathrm{~m}^{2}$.

\subsection{Optimum Turbine Diameter}

This section discusses the analysis of the system's performance with respect to different turbine diameter values. The turbine diameter is a critical parameter to generate significant rotational speed and ensure optimum performance. The dotted line in Figure 6 and Figure 7 shows the experimental data gathered from the laboratory work that has a similar pattern with the theoretical analysis but is slightly reduced in terms of magnitude. It is observed that the measured performance curves pattern 
for both nominal diameters of the pipe size is similar. Furthermore, the overall performance of the 1 " blade is better than the $1 / 2$ " blade.

With reference to the experiment results shown in Figure 6 and Figure 7, the blade with nominal diameter $\varnothing 15 \mathrm{~mm}\left(0.5^{\prime \prime}\right)$ reaches the maximum rotational speed more rapidly compared to the blade with nominal diameter $\varnothing 25 \mathrm{~mm}$ (1.0") when the operating head is equal to $4 \mathrm{~m}$. Practically, the $0.5^{\prime \prime}$ blade will reach a maximum speed of $236 \mathrm{rpm}$ when the flow rate reaches $1.03 \mathrm{~L} / \mathrm{sec}$ and the turbine diameter is $0.5 \mathrm{~m}$. For the 1.0 " blade, the maximum speed of $379 \mathrm{rpm}$ is obtained when the flow rate reaches $1.38 \mathrm{~L} / \mathrm{sec}$, and $0.6 \mathrm{~m}$ diameter turbines are used. Additionally, the magnitude of speed for the 0.5 " blade is approximately $37.7 \%$ lower than the maximum speed of the 1.0 " blade.

Initially, with the short turbine diameter, the difference in speed between theoretic and experiment results is found to be high. However, both speed curves approach each other towards the higher turbine diameter. Basically, for the short turbine diameter, its speed is found to be very sensitive to the mass flow rate, since a little change in mass flow rate can cause a great change to the rotational speed. The small value of $R$ can also have a significant impact on the increase in speed value. Conversely, referring to Eq. (20), towards the longer turbine diameter, the higher value of $R$ causes the speed value to slowly reduce, thus approaching the constant speed value.

Overall, it is observed that the larger the size of the nominal diameter of the PVC pipe, the higher is the maximum rotational speed obtained due to the increment of the mass flow rate. In addition, when the PVC pipe size is increased, it increases the length of the optimum turbine diameter that will be used.

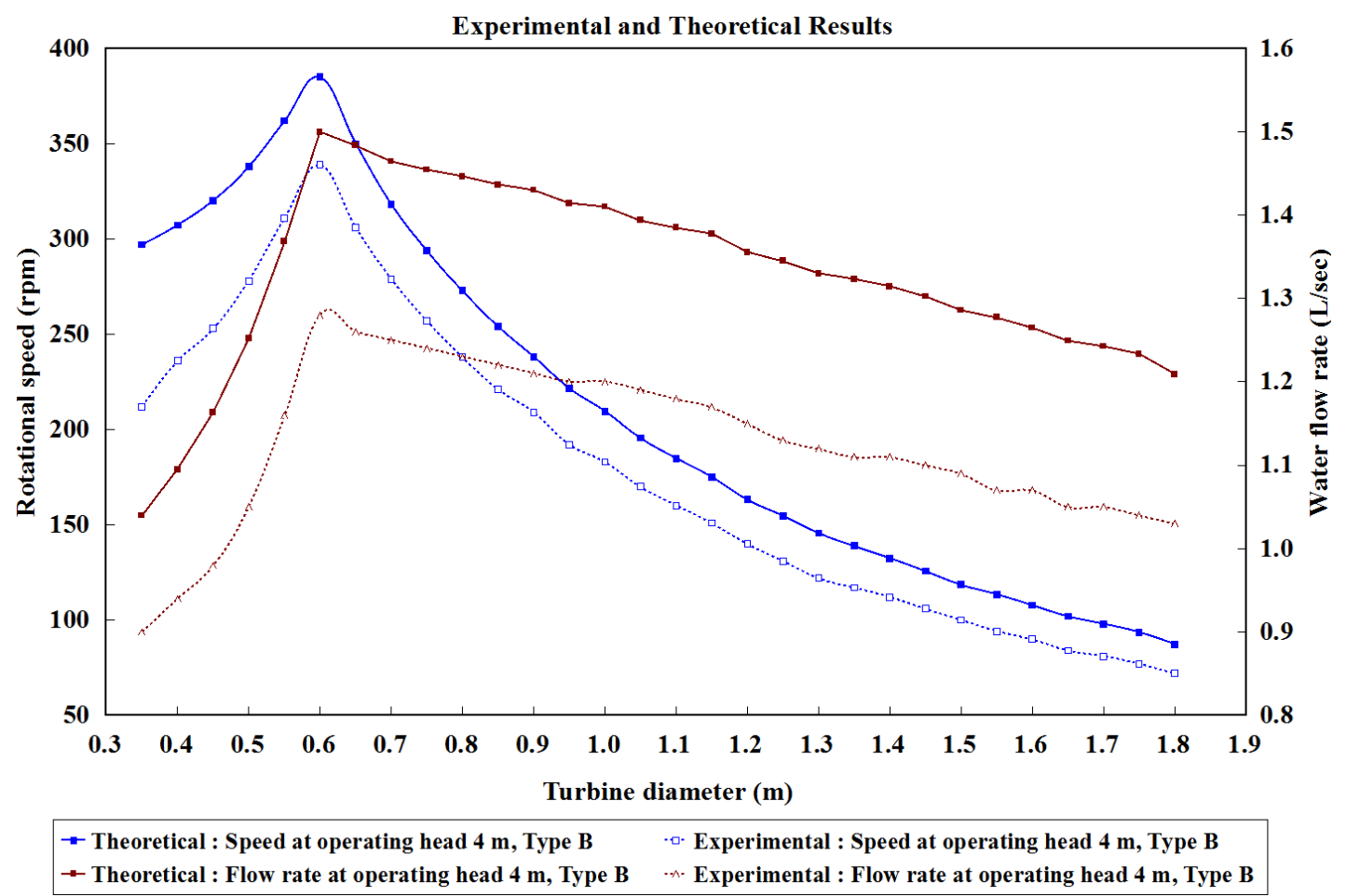

Fig. 6. Experiment and theoretic results for the $4 \mathrm{~m}$ static head (nominal diameter: $\varnothing 25 \mathrm{MM}$ ) 


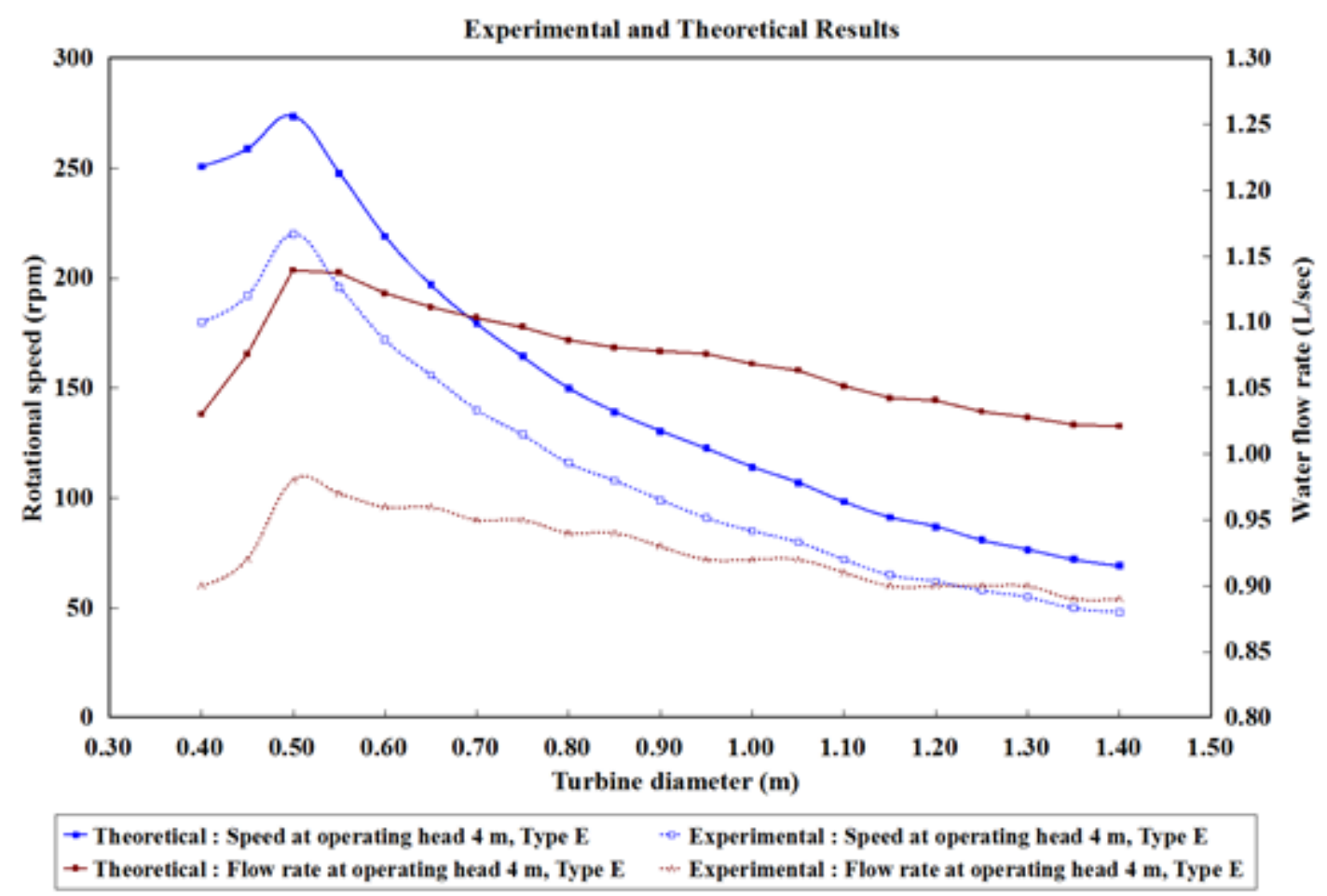

Fig. 7. Experiment and theoretic results for the $4 \mathrm{~m}$ static head (nominal diameter: $\varnothing 15 \mathrm{MM}$ )

The rotational speed of the CPT turbine is high with a linear variation line when the rotor diameter is short. This causes the CPT must be fabricate with a small diameter in order to obtain high angular speed and generate high mechanical power. However, the CPT is difficult to manufacture with a diameter of less than $0.4 \mathrm{~m}$ due to the fixed dimensions of the standard 3' pipe [1]. However, the influence of the operating head on the rotational speeds is less significant at a higher turbine diameter. On the other hand, for a constant water head, the rotational speed reduces with an increase in the CPT turbine diameter.

Conversely, the rotational speed of Z-Blade turbine changes on increasing the turbine diameter in a bell-shaped curve. The peak point of the curve is defined as the maximum rotational speed corresponding to the optimum rotor diameter for a constant operating head. In addition, for a constant operating head, the highest rotor speed did not occur during the short diameter of the blade, which is unlike experienced by the simple reaction turbine such as CPT.

Meanwhile, the maximum rotational speed (peak point) and optimum turbine diameter increase when the water head is increased. By connecting all the peak points in every curve for all water heads, it forms a linear line that also indicates the optimum turbine diameter line. Furthermore, this peak point tends to shift towards the right on the graph as operating head increases, causing the value of the maximum angular speed and optimum turbine diameter to increase. In addition, the effect of the head on the rotational speed diminishes when the rotor blades are focused towards a large diameter.

\subsection{Viscous Losses (K-Factor)}

From the mathematical model and experimental results, the Z-Blade turbine faced a considerable amount of kinetic energy losses and fluid frictional losses. On average, for the $3 \mathrm{~m}$ to $5 \mathrm{~m}$ water head with the nominal diameter of PVC pipe at $\varnothing 25 \mathrm{~mm}(1 ")$, the Z-Blade turbine experienced an increase in fluid frictional loss ( $\mathrm{k}$-factor) from 0.12 to 0.22 . The $\mathrm{k}$-factor is more effective at a higher water head and is caused by the rise in the relative velocity and the mass flow rate due to the centrifugal pumping effect $[7,15]$. As discussed in section 4 , the k-factor for any water head can be calculated 
using Eq. (21). It is worth noting that the parameters such as mass flow rate $\mathrm{m}$ and angular speed $\omega$ can be obtained throughout the experimental work.

Based on the experimental curve shown in Figure 6, when the operational head $H=4 \mathrm{~m}$, the total nozzle exit area $A=1.0 \times 10^{-4} \mathrm{~m}^{2}$ and the optimum radius of the turbine $R=0.3 \mathrm{~m}$, then from the experimental works, the angular velocity of the rotor $\omega=379 \mathrm{rpm}$ and mass flow rate of water through the turbine $\mathrm{m}=1.38 \mathrm{~L} / \mathrm{sec}$ was recorded. By using this information and substitute in Eq. (21), the k-factor for the $\varnothing 25 \mathrm{~mm}$ (1") PVC pipe at the static head $4 \mathrm{~m}$ is 0.16 . With reference to Figure 7 , when $\mathrm{H}=4 \mathrm{~m}, \mathrm{~A}=1.00 \times 10^{-4} \mathrm{~m}^{2}$ but $\mathrm{R}=0.25 \mathrm{~m}$, then for the $\varnothing 15 \mathrm{~mm}\left(1 / 2^{\prime \prime}\right)$ pipe, the experiments give $\omega=236 \mathrm{rpm}$ and $m=1.03 \mathrm{~L} / \mathrm{sec}$. With this information and substitute in Eq. (21), the calculated experimental k-factor for the $\varnothing 15 \mathrm{~mm}\left(1 / 2^{\prime \prime}\right)$ PVC pipe is 0.1 . The experimental data indicates that the 0.5 " blade experienced lower fluid frictional losses compared with the 1 " blade.

Table 1 and Table 2 show several experimental case scenarios to investigate the variation of the k-factor for two sizes of the PVC pipe diameter. There is large variation in the value of the k-factor when the value of the rotational speed is varied by $1 \%$ and the mass flow rate too is varied by $1 \%$. It is worth noting that a small error in reading the rotational speed and the mass flow rate can cause the value of the k-factor calculated to be imprecise.

Table 1

Variation of k-factor for $\varnothing 25 \mathrm{MM}\left(1^{\prime \prime}\right)$ pipe

\begin{tabular}{|c|c|c|c|}
\hline Parameters & $\begin{array}{l}\text { Rotational } \\
\text { speed, } \omega(\mathrm{rpm})\end{array}$ & $\begin{array}{l}\text { Mass flow rate, } \\
\mathrm{m}(\mathrm{kg} / \mathrm{s})\end{array}$ & k-factor \\
\hline Real Case : $\mathrm{H}=4 \mathrm{~m}, \mathrm{~A}=1.00 \times 10^{-4} \mathrm{~m}^{2}, \mathrm{R}=0.25 \mathrm{~m}$ & 236.00 & 1.03 & 0.1 \\
\hline Case $1: \omega$ reduced $1 \%, m$ increased $1 \%$ & 233.64 & 1.04 & 0.07 \\
\hline Case $2: \omega$ reduced $1 \%, m$ unchanged & 233.64 & 1.03 & 0.09 \\
\hline Case 3 : $\omega$ unchanged, $m$ increased $1 \%$ & 236.00 & 1.04 & 0.08 \\
\hline Case $4: \omega$ increased $1 \%, m$ increased $1 \%$ & 238.36 & 1.04 & 0.09 \\
\hline Case $5: \omega$ reduced $1 \%, m$ reduced $1 \%$ & 233.64 & 1.02 & 0.11 \\
\hline Case 6 : $\omega$ increased $1 \%, m$ unchanged & 238.36 & 1.03 & 0.11 \\
\hline Case $7: \omega$ unchanged, $m$ reduced $1 \%$ & 236.00 & 1.02 & 0.12 \\
\hline Case $8: \omega$ increased $1 \%, m$ reduced $1 \%$ & 238.36 & 1.02 & 0.13 \\
\hline
\end{tabular}

Table 2

Variation of k-factor for $\varnothing 15 \mathrm{MM}\left(1 / 2^{\prime \prime}\right)$ pipe

\begin{tabular}{|c|c|c|c|}
\hline Parameters & $\begin{array}{l}\text { Rotational } \\
\text { speed, } \omega(\mathrm{rpm})\end{array}$ & $\begin{array}{l}\text { Mass flow rate, } \\
\mathrm{m}(\mathrm{kg} / \mathrm{s})\end{array}$ & k-factor \\
\hline Real Case : $\mathrm{H}=4 \mathrm{~m}, \mathrm{~A}=1.00 \times 10^{-4} \mathrm{~m}^{2}, \mathrm{R}=0.3 \mathrm{~m}$ & 379.00 & 1.38 & 0.16 \\
\hline Case $1: \omega$ reduced $1 \%, m$ increased $1 \%$ & 375.21 & 1.39 & 0.13 \\
\hline Case 2 : $\omega$ reduced $1 \%, m$ unchanged & 375.21 & 1.38 & 0.14 \\
\hline Case $3: \omega$ unchanged, $m$ increased $1 \%$ & 379.00 & 1.39 & 0.14 \\
\hline Case $4: \omega$ increased $1 \%, m$ increased $1 \%$ & 382.79 & 1.39 & 0.15 \\
\hline$\underline{\text { Case } 5}: \omega$ reduced $1 \%, m$ reduced $1 \%$ & 375.21 & 1.37 & 0.16 \\
\hline Case $6: \omega$ increased $1 \%, m$ unchanged & 382.79 & 1.38 & 0.17 \\
\hline Case 7 : $\omega$ unchanged, $m$ reduced $1 \%$ & 379.00 & 1.37 & 0.17 \\
\hline Case $8: \omega$ increased $1 \%, m$ reduced $1 \%$ & 382.79 & 1.37 & 0.19 \\
\hline
\end{tabular}

The turbine is in an ideal condition when the k-factor is equal to 0 . In other words, the turbine only faces the energy loss caused by the kinetic energy corresponding to the absolute velocity of the exiting water jet. No energy loss is associated with the friction of fluid flow through the turbine [1618]. The k-factor for the 1 " blade is in the range of 0.12 to 0.22 . Meanwhile, the k-factor for the 0.5 " blade in the same range of water head is between 0.09 and 0.13 . 


\subsection{Power Loss and Efficiency}

According to the energy balance equation shown in Eq. (15), the type of loss associated with the water leaving the turbine is known as kinetic energy loss $1 / 2 \mathrm{mV}^{2}$, which occurs at both ideal and practical situations. However, another type of loss, known as fluid frictional loss $1 / 2 m k V_{r}{ }^{2}$, which is related to the water flow through the turbine, only happens at practical situations where $k$-factor $\neq$ $0[7,18]$.

Figure 8 shows that the $k$-factor has a significant impact on the power loss and mechanical power generated of the 1 " blade for the $5 \mathrm{~m}$ water head. The k-factor has a high influence on the power loss from short diameter to optimum turbine diameter, particularly before the maximum rotational speed. With a higher k-factor, the Z-Blade turbine experiences higher power loss particularly at short turbine diameter. Over most of the range of the k-factor, all power losses have higher decreasing rate with increasing rotational speed towards the optimum turbine diameter. However, after the maximum rotational speed is achieved, the effect of $k$-factor is insignificant. All the power losses are reduced almost linearly, approaching each other with reducing rotational speed towards the long diameter. It is good to note that, tangential velocity of the nozzles approaching the relative velocity towards the higher turbine diameter [18]. Hence, the absolute velocity $\mathrm{V}_{\mathrm{a}}$ in the component $1 / 2 \mathrm{mV}_{\mathrm{a}}{ }^{2}$ will be reduced asymptotically approaching zero.

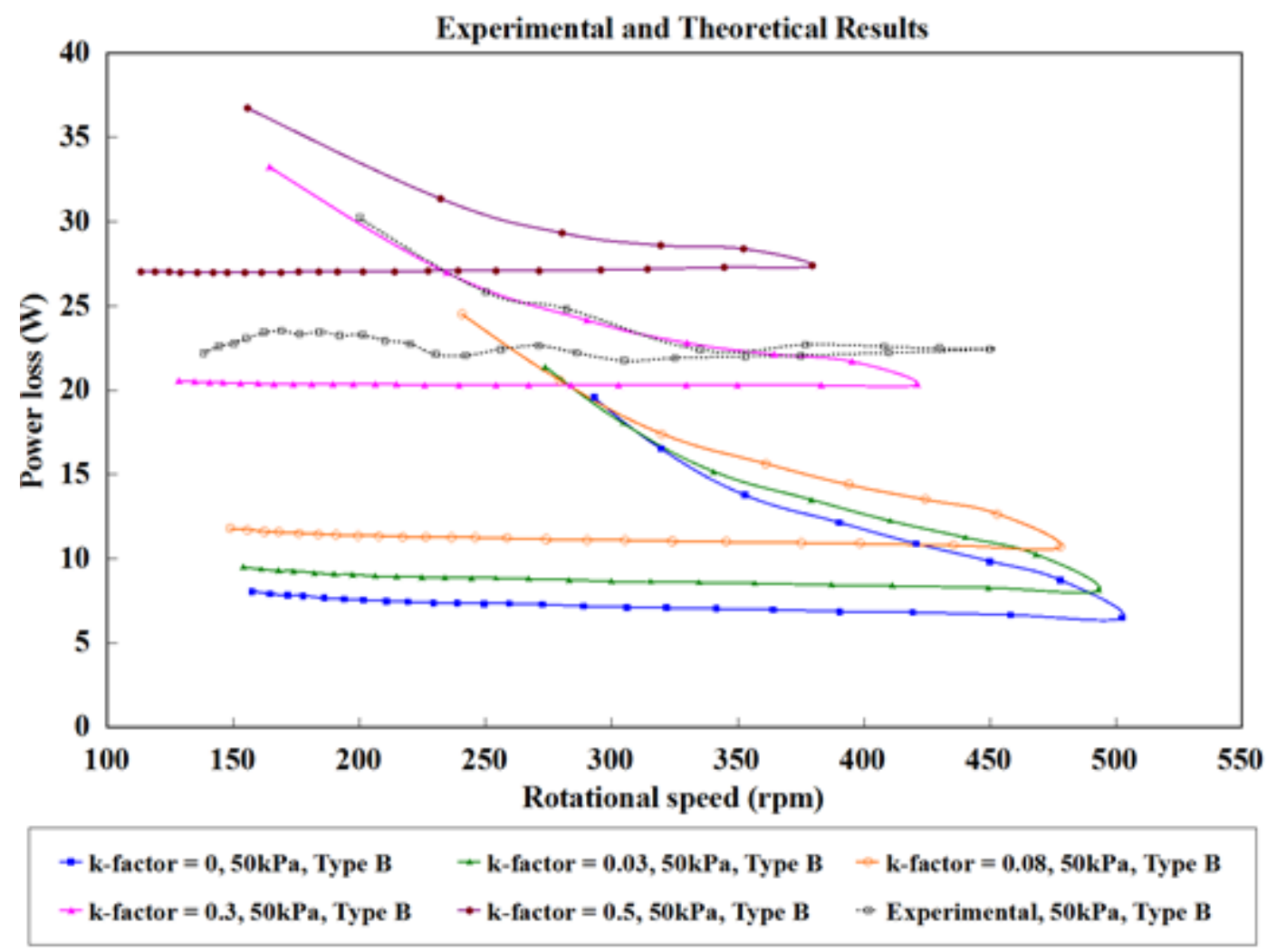

Fig. 8. Effect of k-factor on the power loss

Conversely, the k-factor highly influences the mechanical power after the maximum rotational speed is obtained. Towards long turbine diameter, not much different in the power loss. Hence, with varying the k-factor, the magnitude of potential energy component highly affected by any small changes in flow rate and simultaneously it will farther different in the magnitude of mechanical power. 
Initially, the mechanical power has a higher rate of rise towards the maximum rotational speed. This happens due to the mass flow rate and the angular speed of the rotor having a high rate of increase from the short diameter to optimum turbine diameter. However, the rotor speed then reduces drastically and the mechanical power is slightly increased linearly towards the long turbine diameter. Furthermore, the mechanical power still increases in a slow rate towards the long turbine diameter because the mass flow rate continues to increase due to the centrifugal head being affected by the increment of the rotor length.

Figure 9 shows that the efficiency for the Z-Blade turbine at $5 \mathrm{~m}$ water head is about $92 \%$ at the highest rotational speed. The effect of the k-factor diminishes towards the long turbine diameter as all the efficiency curves approach each other. On comparing the ideal conditions with the experiment curve $(\mathrm{k}$-factor $=0.22$ ), the fluid friction factor resulted in a significant (almost $24 \%$ ) drop in efficiency, especially before the maximum rotational speed was achieved. Besides, when the value of the kfactor is increased, the efficiency curve for the other k-factor moves farther, getting away from the ideal condition curve $(k$-factor $=0)$. The increment of the $k$-factor will reduce the relative velocity and angular speed of the rotor, simultaneously reducing the percentage of efficiency. This will also cause the mechanical power output to reduce, since the mass flow rate and angular velocity is decreased.

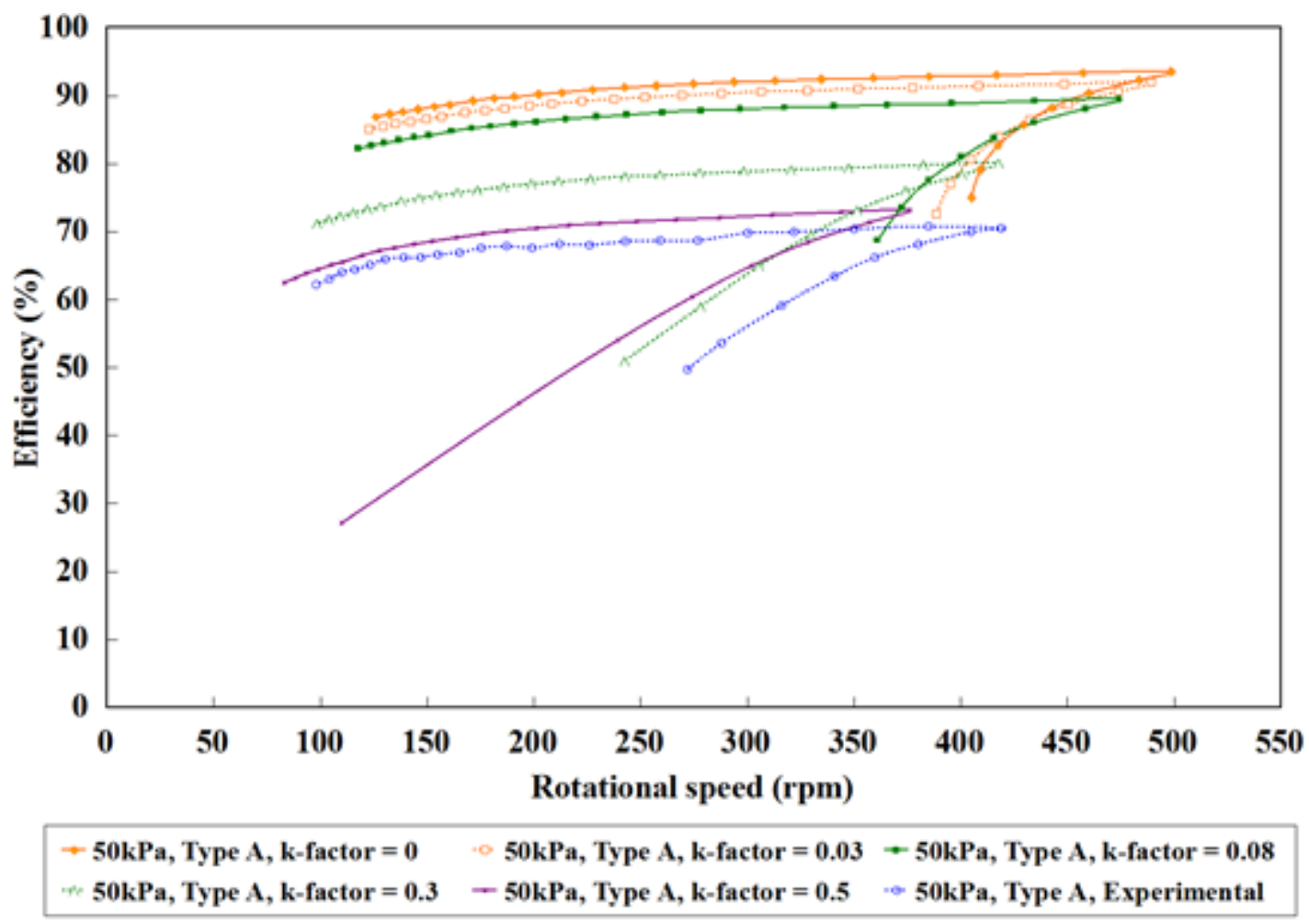

Fig. 9. Efficiency of Z-Blade turbine at $5 \mathrm{~m}$ water head

\section{Conclusions}

This paper investigates the study of Z-Blade reaction type water turbine performance characteristics, both theoretically and experimentally. Overall, the results showed that the performance of 1 " blade was better compared to $1 / 2$ " blade, while the performance of both pipe sizes increased when the operational water head was increased. Furthermore, it was observed that the pattern of the measured performance curves for both sizes of the pipe is almost similar. It is interesting to note that the larger the size of the nominal diameter pipe, the higher was the maximum rotational speed (optimum diameter) obtained, after simultaneously increasing the quantity of water 
flow through the turbine. For a constant water head, the larger the values of k-factor, the farther its overall performance moves away from ideal conditions. This is due to the reduction in the mass flow rate and angular speed of the rotor.

\section{Acknowledgement}

The authors would like to thank the Ministry of Higher Education, Malaysia for funding this research (PRGS/1/2014/TK06/FTK/02/T00011 \& FRGS/2012/FTK/TK07/03/1/F00145), and Universiti Teknikal Malaysia Melaka for providing the laboratory facilities and technical support.

\section{References}

[1] Farriz, M. B., H. Boejang, M. Masjuri, M. S. M. Aras, N. H. A. Razik, S. Mate, and K. Sopian. "Evolution of simple reaction type turbines for pico-hydro applications." Jurnal Teknologi 77, no. $32 \quad$ (2015). https://doi.org/10.11113/jt.v77.6980

[2] Jabar, Siti Norbakyah, and Salisa Abdul Rahman. "A Comparative Study on Components Sizing for Conventional Boat and Pherb Powertrains using Water Driving Cycle." Journal of Advanced Research in Applied Sciences and Engineering Technology 16, no. 1 (2019): 41-48.

[3] Dewatama, D., M. Fauziah, H. K. Safitri, and S. Adhisuwignjo. "Design and implementation: portable floating picohydro." In IOP Conference Series: Materials Science and Engineering, vol. 732, no. 1, p. 012049. IOP Publishing, 2020. https://doi.org/10.1088/1757-899X/732/1/012049

[4] Farriz, M. B., H. Boejang, M. Masjuri, M. S. M. Aras, N. H. A. Razik, S. Mate, and K. Sopian. "Evolution of simple reaction type turbines for pico-hydro applications." Jurnal Teknologi 77, no. $32 \quad$ (2015). https://doi.org/10.11113/it.v77.6980

[5] Corio, Dean, and Kiki Kananda. "Analisa Potensi Embung Itera Sebagai Pembangkit Listrik Tenaga Pico Hydro (PLTPH)." Jurnal Nasional Teknik Elektro 8, no. 3 (2019): 97-103. https://doi.org/10.25077/jnte.v8n3.691.2019

[6] Paudel, Pradeep, and Shailesh Wasti. "Peak Demand Management in Micro Hydro using Battery Bank." Hydro Nepal: Journal of Water, Energy and Environment 22 (2018): 34-40. https://doi.org/10.3126/hn.v22i0.18994

[7] Date, Abhijit, and Aliakbar Akbarzadeh. "Design and analysis of a split reaction water turbine." Renewable Energy 35, no. 9 (2010): 1947-1955. https://doi.org/10.1016/i.renene.2010.01.023

[8] Warjito, Warjito, Sanjaya BS Nasution, Muhammad Farhan Syahputra, Budiarso Budiarso, and Dendy Adanta. "Study of turbulence model for performance and flow field prediction of pico hydro types propeller turbine." CFD Letters 12, no. 8 (2020): 26-34. https://doi.org/10.37934/cfdl.12.8.2634

[9] Lahimer, A. A., M. A. Alghoul, Kamaruzzaman Sopian, Nowshad Amin, Nilofar Asim, and M. I. Fadhel. "Research and development aspects of pico-hydro power." Renewable and Sustainable Energy Reviews 16, no. 8 (2012): 5861 5878. https://doi.org/10.1016/i.rser.2012.05.001

[10] Yaakub, M. Faizal, M. Farriz Basar, F. Hanim Mohd Noh, and Hambali Boejang. "Pico-hydro Electrification from Rainwater's Gravitational Force for Urban Area." Telkomnika 16, no. 3 (2018): 997-1003. https://doi.org/10.12928/telkomnika.v16i3.8076

[11] "Economic Analysis on Design of a Simple Hydraulic Reaction Type Turbine for Low-Head Low-Flow Pico Hydro." International Journal of Innovative Technology and Exploring Engineering 9, no 12 (2019): 3876-3980. https://doi.org/10.35940/ijitee.B7257.129219

[12] Chen, Jinbo, and Abraham Engeda. "Standard module hydraulic technology: A novel geometrical design methodology and analysis for a low-head hydraulic turbine system, Part I: General design methodology and basic geometry considerations." Energy 196 (2020): 117151. https://doi.org/10.1016/i.energy.2020.117151

[13] Ab Ghani, Sharin, and Idris Mohd Yusoff. "Comparative Study of Residential Lighting Technologies." Journal of Advanced Research in Applied Sciences and Engineering Technology 14, no. 1 (2019): 8-20.

[14] Karrupusamy, P.. "Performance Analysis of Multiple Pico Hydro Power Generation." (2020). https://doi.org/10.36548/jeea.2020.2.005

[15] Date, Abhijit, and Aliakbar Akbarzadeh. "Design and cost analysis of low head simple reaction hydro turbine for remote area power supply." Renewable Energy 34, no. $2 \quad$ (2009): $409-415$. https://doi.org/10.1016/j.renene.2008.05.012

[16] Date, Abhijit, Ashwin Date, and Aliakbar Akbarzadeh. "Investigating the potential for using a simple water reaction turbine for power production from low head hydro resources." Energy Conversion and Management 66 (2013): 257-270. https://doi.org/10.1016/j.enconman.2012.09.032 
[17] Date, Abhijit, Aliakbar Akbarzadeh, and Ashwin Date. "Performance investigation of a simple reaction water turbine for power generation from low head micro hydro resources." Smart Grid and Renewable Energy 3, no. 03 (2012): 239. https://doi.org/10.4236/sgre.2012.33033

[18] "A Novel Z-blade Reaction Type Turbine for Low Head Low Flow Water Condition." International Journal of Innovative Technology and Exploring Engineering 9, No (2020): 1370-1374. https://doi.org/10.35940/ijitee.C8175.019320

[19] Jamil, Muhammad Mahmud, Nor Azwadi Che Sidik, and Siti Nurul Akmal Yusof. "Solar Collector Application using Nanofluid in Thermosyphon." Journal of Advanced Research in Materials Science 65, no. 1 (2020): 1-15. https://doi.org/10.37934/arms.65.1.115

[20] Ren, Hew Wei, Fatimah Al Zahrah Mohd Saat, Fadhilah Shikh Anuar, Mohd Arizam Abdul Wahap, Ernie Mat Tokit, and Tee Boon Tuan. "Computational Fluid Dynamics Study of Wake Recovery for Flow Across Hydrokinetic Turbine at Different Depth of Water." CFD Letters 13, no. 2 (2021): 62-76. https://doi.org/10.37934/cfdl.13.2.6276

[21] Radzi, Abdul Qoiyum Mohd, and Noorazizi Mohd Samsuddin. "Design optimization of savonius wind turbine using CFD-particle swarm optimization with power flow validation experimentally." CFD Letters 12, no. 10 (2020): 27-39. https://doi.org/10.37934/cfdl.12.10.2739

[22] Siswantara, Ahmad Indra, Budiarso Budiarso, Aji Putro Prakoso, Gun Gun R. Gunadi, Warjito Warjito, and Dendy Adanta. "Assessment of turbulence model for cross-flow pico hydro turbine numerical simulation." CFD Letters 10 , no. 2 (2018): 38-48. 